\title{
Menos Estigma, Pouco Aprofundamento: \\ Uma Análise de Enquadramento Noticioso sobre o Direito ao Aborto
}

Less Stigma, Less Depth: an analysis of the news framework on the right to abortion

\section{Luciane Leopoldo Belin}

Mestre e doutoranda em Comunicação pelo PPGCOM/UFPR. Bolsista CAPES. Pesquisadora do grupo de pesquisa em Comunicação e Participação Política (COMPA). lucianebelin@gmail.com

\section{Carla Rizzotto}

Doutora em Comunicação. Professora e pesquisadora do Departamento de Comunicação e do PPGCOM/UFPR. Pesquisadora do grupo de pesquisa em Comunicação e Participação Política (COMPA). carlarizzotto84@gmail.com

\section{RESUMO}

0 artigo discute o enquadramento noticioso sobre a pauta do aborto no Brasil em 85 notícias publicadas ao longo de 2019 em quatro sites: Folha de S. Paulo, O Estado de S. Paulo, Huffpost Brasil e Nexo Jornal. Aplicando o método de análise de enquadramento com variáveis baseadas em Semetko e Valkenburg (2000) e Iyengar (1990), busca-se responder à seguinte questão: quais os enquadramentos predominantes na cobertura noticiosa sobre a temática do aborto em portais jornalísticos tradicionais e nativos digitais no Brasil em 2019? Os resultados apontam para uma cobertura majoritariamente favorável ou neutra sobre o tema, porém ainda "Episódica", ou seja, com pouco espaço para aprofundamento. As matérias recorrem principalmente a fontes políticas, ativistas pró-aborto e, em menor número, religiosas. As publicações avançam no sentido de tratar a questão sob o frame da responsabilidade e das consequências econômicas e sociais, mas também é significativa a presença dos de moralidade e conflito. PALAVRAS-CHAVE: aborto; enquadramento; comunicação; jornalismo; feminist media studies 


\section{ABSTRACT}

The article discusses the news frames of the coverage of four websites - Folha de $S$. Paulo, $O$ Estado de S. Paulo, Huffpost Brasil and Nexo Jornal - in 85 news about abortion published throughout 2019 in Brazil. With the framework analysis as methodology, based on Semetko and Valkenburg (2000) and Iyengar (1990), we seek to answer the following question: what are the predominant frameworks in the news coverage on the theme of abortion in traditional and digital native news portals in Brazil in 2019? The results point to a mostly favorable or neutral coverage of the topic, but still "Episodic", that is, relatively shallow. The stories mainly appeal to political, pro-abortion activists and, to a lesser extent, religious sources. The publications advance towards dealing with the issue under the framework of responsibility and economic and social consequences, but the presence of morality and conflict frames is also significant.

KEYWORDS: abortion; framework; communication; journalism; feminist media studies

\section{RESUMEN}

El artículo analiza el marco informativo sobre la agenda del aborto en Brasil en 85 noticias publicadas a lo largo de 2019 en cuatro sitios web: Folha de S. Paulo, O Estado de S. Paulo, Huffpost Brasil y Nexo Jornal. Aplicando el método de análisis de marcos con variables basado en Semetko y Valkenburg (2000) e Iyengar (1990), buscamos dar respuesta a la siguiente pregunta: ¿Cuáles son los frames predominantes en la cobertura informativa sobre el tema del aborto en los portales de noticias tradicionales y digitales en Brasil en 2019? Los resultados apuntan a una cobertura mayoritariamente favorable o neutra sobre el tema, pero aún "episódica", es decir, superficial. Las historias provienen principalmente de fuentes políticas, activistas pro-aborto y, en menor medida, religiosas. Las publicaciones avanzan hacia el abordaje del tema en el marco de la responsabilidad y las consecuencias económicas y sociales, pero la presencia de moralidad y conflicto también es significativa.

PALABRAS CLAVE: aborto; frame analisys; comunicación; periodismo; feminist media studies

Submetido em 29 de Agosto de 2020

Aceito em 24 de Abril de 2021

\section{Introdução}

Ao longo de 2019, primeiro ano do governo Jair Bolsonaro no Brasil, a temática do aborto foi mobilizada na imprensa e na opinião pública brasileiras a partir de diversos eventos nacionais e internacionais. Muito ativada durante a campanha bolsonarista enquanto esse era candidato à presidência, a interrupção voluntária da gestação é um 
tema que suscita discussões frequentemente polarizadas, seja em conversas informais, seja na esfera pública.

Para compreender de que maneira a cobertura midiática sobre o tema se desenvolveu ao longo deste primeiro ano de mandato, o artigo em tela analisou 85 notícias relacionadas ao aborto, publicadas ao longo de 2019 na Folha de S. Paulo, n'0 Estado de S. Paulo, no Nexo Jornal e no Huffpost Brasil. 0 objetivo da análise é responder à seguinte questão: Quais os enquadramentos predominantes na cobertura noticiosa sobre a temática do aborto em sites de jornais tradicionais e nativos digitais no Brasil em 2019? Interessa compreender quais enquadramentos e níveis de profundidade a imprensa trouxe a uma pauta tida como progressista no ano inaugural de mandato do primeiro presidente conservador em 15 anos.

0 artigo é estruturado da seguinte maneira: no primeiro tópico, parte-se de uma breve contextualização sobre opinião pública, legislação e dados de saúde pública referentes à interrupção voluntária da gestação no país, seguida de uma revisão de literatura sobre as abordagens dadas pela imprensa ao tema, seja isoladamente, seja atrelada a campanhas eleitorais que empregaram a temática como ferramenta eleitoreira.

0 tópico seguinte é dedicado a apresentar a metodologia que norteia a realização da pesquisa, a análise de enquadramento. Com diferentes vertentes e técnicas possíveis, essa vertente teórico-metodológica compreende que os veículos midiáticos têm a função de enquadrar o mundo, criando molduras a partir das quais a realidade é observada nos jornais e revistas, nas telas de computador e de televisão. Nesta investigação, as autoras partiram das perspectivas de Semetko e Valkenburg (2000) e Iyengar (1990) para elaborar as duas principais variáveis observadas - o tipo de enquadramento e o nível de contextualização - desenvolvidas ainda no segundo tópico, onde são apresentados os primeiros dados obtidos na análise.

No terceiro e último tópico, são discutidos os principais resultados encontrados. 0 levantamento mostrou que a cobertura midiática sobre aborto em 2019 foi majoritariamente "Episódica", ou seja, centrou-se em eventos específicos, com notícias em sua maioria factuais e superficiais. Pouco mais de $25 \%$ dos textos publicados no período apresentaram contextualização "Temática”, aprofundada o suficiente para dar conta das 
principais nuances que cercam o tema. Além disso, a pesquisa mostra uma presença significativa de textos dedicados a explorar o viés do "Conflito" e da "Moralidade", o que não inibe iniciativas de trazer dados que permitam ao leitor conhecer camadas mais profundas e complexas sobre o tema, discutindo os vieses da "Responsabilidade" e das "Consequências Econômicas".

\section{Aborto: imprensa e sociedade}

Segundo a pesquisa Global Views on Abortion 20201, que compara a postura de 25 países com representantes de todas as regiões do mundo para elaborar uma média global sobre o tema, $16 \%$ dos brasileiros acreditam que o aborto deve ser um direito da mulher, permitido sempre que a própria desejar. Ainda no Brasil, $37 \%$ defendem a prática em caso de estupro, 21\% quando há risco à saúde da gestante e 13\% são contrários em qualquer circunstância. Os números estão abaixo da média global - em que 44\% são a favor do direito do aborto em qualquer circunstância - e são ainda menores do que a mesma pesquisa constatou no ano anterior no país. A soma de favoráveis em qualquer caso e favoráveis em caso de estupro, que era de 61\%, baixou para 53\%.

Os índices abaixo da média mundial se refletem na pouca movimentação do país no sentido de atualizar a legislação que rege a interrupção voluntária da gestação, calcada numa lei de 1940. Os artigos 124 a 128 da Lei no 2.848 tornam crime o aborto no Brasil, salvo em casos de gestação fruto de estupro e risco de morte à mulher. Mais tarde, em 2012, uma atuação do Supremo Tribunal Federal acrescentou às exceções os casos em que o feto é anencéfalo.

Em contrapartida, os dados de saúde pública evidenciam que um altíssimo número de abortos é realizado clandestinamente no país todos os anos. Segundo a Pesquisa Nacional do Aborto (DINIZ, 2016), uma a cada 5 mulheres brasileiras de até 40 anos já interrompeu ao menos uma gestação até esta idade. 0 relatório "Aborto: por que precisamos descriminalizar", apresentado pelo Anis - Instituto de Bioética ao Supremo Tribunal Federal na Audiência Pública da ADPF 442, realizada em 2018, aponta que 4,7

\footnotetext{
1 “De 25 países, Brasil é o segundo menos favorável à legalização do aborto". Disponível em: <https://bit.ly/31DVFd1>. Acesso em 22/08/2020.
}

\section{Dossiê Feminismos vitais - https://revistaecopos.eco.ufrj.br/}


milhões de mulheres que têm entre 18 e 39 anos já realizaram aborto no país. (ANIS, 2018, p. 1). Mais recentemente, dados do Sistema de Informações Hospitalares do SUS (SIH/SUS), do Ministério da Saúde ${ }^{2}$ apontam os seguintes números de internações por "aborto espontâneo, aborto por razões médicas e outras gravidezes que terminam em aborto": 195.994 em 2019, 181.678 em 2020 e, nos três primeiros meses de 2021, 42.945 mulheres hospitalizadas.

Apesar da recorrência com que é praticado, encoberto por um véu de silêncio, medo e estigma, o aborto carrega em si nuances relacionadas a questões de gênero, saúde pública, classe, raça, moralidade e religião, de forma que discussões sobre esta temática costumam ser polarizadas e a cobertura midiática sobre ela, cautelosa.

A descriminalização do aborto e o tratamento dado pelos veículos noticiosos a esta discussão, central ao movimento feminista, estão entre as pautas que interessam aos feminist media studies, que incorporam os estudos dedicados a analisar a relação entre gênero, feminismo e imprensa, tratando também de aspectos como a representação das mulheres tanto nos produtos midiáticos quanto na produção e recepção dos conteúdos.

Segundo Sarmento (2019, p. 133), embora se possa rastrear os primeiros esforços no sentido de uma crítica de mídia feminista aos anos 50 e 60, passando também pela contribuição das mulheres nos Estudos Culturais britânicos, essa perspectiva da análise midiática ganhou força nos anos 90 , com pesquisas que se debruçam sobre os retratos das mulheres no jornalismo e no entretenimento, em jornais, revistas, na televisão, no rádio e, mais tarde, na internet.

Independentemente do meio analisado, no entanto, o papel da mídia para as discussões relacionadas a gênero é crucial, uma vez que

\begin{abstract}
os meios de comunicação são arenas fundamentais para a compreensão da importante visibilidade ampliada de pautas (como violência doméstica, por exemplo) ou da construção mais pejorativa do feminismo. (...) Não investigá-los é perder uma parte significativa do entendimento sobre como a "identidade pública" ou a "memória popular" sobre o feminismo é construída ou circula ao longo do tempo". (SARMENTO, 2019, p. 142)
\end{abstract}

2 Dados extraídos do Sistema de Informações Hospitalares do SUS. Disponível em:
<http://tabnet.datasus.gov.br/cgi/tabcgi.exe?sih/cnv/niuf.def>. Acesso em 28/05/2021.

Dossiê Feminismos vitais - https://revistaecopos.eco.ufrj.br/

ISSN 2175-8689 - v. 24, n. 1, 2021

DOI: 10.29146/ecopos.v24i1.27609 


\section{DOSSIÊ}

Cada vez mais encarado sob uma perspectiva interseccional, o debate sobre questões atreladas aos direitos das mulheres perpassa também as de raça, classe e identidades de gênero. Os diferentes ativismos cobram dos meios de comunicação que, ao debater temas relacionados às mulheres, sejam considerados estes recortes transversais e o contexto em que as pautas estão inseridas. 0 caso do direito ao aborto é, também, alvo destes questionamentos. Uma vez que as mulheres mais vitimizadas pelas tentativas de aborto clandestino são as negras, indígenas e as que vivem nas periferias (DINIZ, 2016), o jornalismo precisa apresentar o cenário quando noticia casos de aborto, por exemplo.

A presença dessas questões transversais foi um dos critérios levados em consideração ao operacionalizar as variáveis a partir das quais foi analisado o conjunto de notícias que compôs o corpus empírico deste artigo.

\subsection{0 aborto sob a lente da imprensa}

Pesquisas que se dedicam a compreender de que forma o aborto é apresentado pelos meios de comunicação trazem resultados variados. No final da década de 90, a pesquisa Aborto e Mídia (MELO, 1997) analisou o considerável espaço dado ao assunto por quatro jornais - Folha de S. Paulo, O Estado de S. Paulo, Jornal do Brasil e O Globo que entre 1996 e 1997 somava 1.135 notícias. Publicadas no contexto de aprovação do Projeto de Lei no. 20/91, que obriga o Sistema Único de Saúde a realizar o procedimento nos casos previstos pela legislação, as matérias se dividiam entre $45 \%$ favoráveis ao direito ao aborto, 28\% contrárias e 26\% neutras, em 1996. Em 1997, os números eram de 44\%, 25\% e 31\%, respectivamente.

$\mathrm{Na}$ ocasião, a pesquisadora verificou ainda uma mudança no perfil dos entrevistados para as matérias. "Um dos principais destaques da cobertura foi que a demanda pelo direito ao aborto não é mais um discurso protagonizado apenas por feministas" (MELO, 1997, p. 407). Ela aponta para a entrada de outros agentes na argumentação: médicos, conselhos de medicina, advogados e juristas, o que transfere a discussão do ponto de vista ativista ao da saúde pública e dos direitos e concede aos discursos um tom técnico, menos religioso, ideológico e ativista. 
Ao se debruçar sobre as matérias a respeito do aborto na Folha de S. Paulo entre 2003 e 2008, Pinho (2008) identificou que 10,6\% apresentavam um viés contrário ao direito das mulheres de abortar, enquanto $16,5 \%$ se posicionavam claramente a favor da descriminalização ou da ampliação das possibilidades de aborto legal.

Uma terceira investigação, realizada por Cukierkorn e Batista (2016), analisa 25 notícias publicadas pelo jornal 0 Estado de S. Paulo ao longo do ano de 2010, identificando baixa presença de conteúdos que trazem pontos de vista das mulheres, ao mesmo tempo em que evidenciam pontos de vista de indivíduos representantes religiosos e políticos. Esses dois atravessamentos - político e religioso - serão discutidos a seguir.

\subsection{Aborto como ferramenta eleitoral}

Em 2010, durante a campanha eleitoral que culminou com a eleição da presidenta Dilma Rousseff (PT) para seu primeiro mandato no executivo federal, a interrupção voluntária da gestação foi uma das pautas mais discutidas nos debates e entrevistas com a então candidata e seu principal oponente, José Serra (PSDB). 0 modo como a imprensa tratou a questão durante aquelas eleições se tornou objeto de diversos estudos (MANTOVANI, 2016; 2019; FONTES, 2012; MACHADO, 2012; LUNA, 2014) acerca das relações entre a imprensa brasileira e a parcela do movimento feminista que defende a descriminalização do aborto, bem como o posicionamento dos veículos de comunicação a favor de um viés conservador e a exclusão da perspectiva da saúde pública do debate. Também aparecem análises sobre os impactos da instrumentalização desta pauta para a imagem dos candidatos em campanha e para a formação de opiniões na esfera pública, além de investigações que verificam a força de alguns agentes na argumentação, como os atores religiosos e político-partidários, que buscam controlar a narrativa e criar uma aura de estigmatização em torno das mulheres que abortam.

\footnotetext{
Observar a construção da narrativa jornalística por meio de estereótipos permite verificar as complexidades e contradições dentro do próprio espaço noticioso. Ao mesmo tempo em que existem discursos que promovem avanços em relação a posições conservadoras e hierárquicas, por outro lado, essa mesma esfera simbólica pode sustentar discursos que não confrontam o poder e a ordem social estabelecidas. Pelo contrário, as legitimam. (MANTOVANI, 2019, p. 187).
} 


\section{DOSSIE}

A autora centrou suas pesquisas em quatro grandes veículos noticiosos brasileiros - Folha de S. Paulo, O Globo, O Estado de S. Paulo e Jornal Nacional - e entendeu que o discurso destes canais tende a "reforçar estereótipos de gênero, raça e posições de classe" (Idem, p. 167) por meio das assimetrias empregadas na construção da narrativa, como a escolha das fontes, o viés do texto e a própria estrutura das reportagens.

Mantovani identificou que mais da metade dos textos estavam mais preocupados com a relação do tema com as estratégias eleitorais dos candidatos (52\%), enquanto 15\% favoreciam perspectivas religiosas contrárias ao aborto (MANTOVANI, 2019, p. 180). 0 caso das eleições de 2010 é apenas um exemplo, embora seja emblemático porque evidenciou que, "quando necessário, parte da grande imprensa usa o discurso antiabortista para alvejar os candidatos de seu desagrado" (MIGUEL, 2016, P. 61).

Essa tendência a transformar a questão do aborto em ferramenta eleitoral também é identificada no trabalho de Luna (2014), que analisou a cobertura dos casos Jandira, Elizângela e a Operação Herodes, também em período pré-pleito. As mortes de duas mulheres que haviam buscado clínicas de abortamento clandestinas para interromper uma gestação indesejada pautou o jornal 0 Globo, em conteúdos que priorizavam entre as fontes de informação os familiares das duas vítimas e autoridades médicas e do Direito, negligenciando feministas. A maior parte das publicações tratava dos casos e seus desdobramentos em termos de investigação, evitando discussões mais abrangentes sobre o contexto do aborto ilegal no Brasil.

Em maio de 2018, também ano eleitoral, o assunto ganhou projeção quando o Supremo Tribunal Federal convocou uma audiência pública ${ }^{3}$ para avaliar a constitucionalidade da criminalização do aborto, a partir de uma ação ajuizada pelo Partido Socialismo e Liberdade (PSOL). 0 tema foi recorrente na imprensa nos meses seguintes, pautado pela votação da descriminalização na Argentina e pelas próprias eleições presidenciais brasileiras.

Na campanha eleitoral daquele ano, a temática ganhou espaço como uma das chamadas "pautas de costume" ideológico-conservadoras, as quais protagonizaram a

\footnotetext{
3 Processo eletrônico público ADPF 442. Disponível em: $<$ https://portal.stf.jus.br/processos/detalhe.asp?incidente=5144865> . Acesso em 28/05/2021.
} 
candidatura de Jair Bolsonaro, pelo PSL. Antes e depois de eleito presidente, o mesmo afirmou em diversas ocasiões que, caso o Congresso e o Senado Federal aprovassem a descriminalização do aborto, ele vetaria a alteração ${ }^{4}$.

Como as investigações citadas ilustram, o assunto periodicamente ganha espaço na mídia, seja quando um caso particular chama a atenção dos jornalistas ou quando discussões a respeito são motivadas pelas próprias instituições. Essa aparição constante e sob múltiplas perspectivas também se verificou em 2019. Para analisar o tom da cobertura neste contexto, foi empregada a metodologia da análise de enquadramento, que será apresentada a seguir.

\section{Enquadramento midiático}

A literatura em torno das abordagens possíveis para analisar o enquadramento midiático é robusta e dá conta de vários vieses. Com distintas metodologias, as chamadas frame analysis buscam compreender os critérios a partir dos quais a notícia é construída e as consequências destes recortes para a interpretação da mesma. Mendonça e Simões (2012) chamam a atenção para a diversidade de abordagens metodológicas possíveis e atentam para o risco de dispersão do conceito de enquadramento se aplicado em tantos estudos, de diferentes maneiras, sem que seja discutido quais direcionamentos teóricos embasam a pesquisa em questão.

Alinhados com Erving Goffman e Robert Entman, dois expoentes no tratamento do tema, os autores separam os estudos de enquadramento em três vertentes: a primeira concentra-se na situação comunicativa, a segunda inclui os estudos que analisam o conteúdo dos enunciados e a última debruça-se sobre os efeitos da seleção de frames na construção do texto (frame effects). Para Mendonça e Simões, a terceira vertente contradiz, em parte, o próprio conceito de enquadramento, à medida em que não se pode dizer quais efeitos são gerados sobre cada sujeito ou que a construção dos frames seja sempre puramente estratégica. Por isso, recomendam uma abordagem que possa

\footnotetext{
4 “Homem não deve intervir na decisão da mulher sobre aborto, diz Bolsonaro". Disponível em: <https://bit.ly/3beCUA4 >. Acesso em 28/05/2021.
} 
ressaltar a dimensão pragmática da linguagem, atentando para o contexto de produção dos discursos e para os elementos metacomunicativos que estão dados pela própria situação interativa. Além disso, o viés enfatiza que quadros são construções culturais profundas que não estão à disposição dos atores sociais, embora tais atores façam parte de contínuos jogos de forças para alterar os rumos das interpretações de certos fenômenos. (MENDONÇA, SIMÕES, 2012, p. 197)

Ao adotar esta perspectiva, a análise empreendida neste artigo olha para o conteúdo dos enunciados de forma situada no contexto social no qual foram produzidas as notícias.

\subsection{Variáveis empregadas}

A metodologia utilizada divide as variáveis entre uma parcela Situacional, que objetiva compreender o contexto no qual as notícias estão inclusas, e uma Metacomunicativa, que resgata os recursos utilizados no conteúdo para construção dos frames.

Como variáveis Situacionais foram consideradas: 1) Site; 2) Tipo do site (Quality Paper ou Nativo Digital); 3) Editoria; 4) Gênero do jornalista que assina a matéria (Mulher, Homem, Autoria Coletiva ou Não Assinada). Entende-se como variáveis de conteúdo, ou seja, Metacomunicativas, o 5) Ponto de vista do texto (Favorável, Contrário ou Neutro); 6) Fontes de informação empregadas (Ativista Favorável, Ativista Contrário, Figura Política, Figura ou Órgão Médico, Figura Jurídica; Figura Religiosa; Personagem Mulher; Personagem outro; Dados); 7) Nível de contextualização (Temático ou Episódico); 8) Tipo de Enquadramento (Moralidade; Responsabilidade; Consequências Econômicas; Interesse Humano; Conflito).

A V7) Nível de Contextualização pode ser "Episódica” ou “Temática” (IYENGAR, 1990; SILVA, 2017) e diz respeito ao esforço do conteúdo para explorar diferentes aspectos e perspectivas, baseado na ideia de que há notícias factuais que apenas narram um fato pontual, enquanto outras coberturas o vinculam a um cenário mais amplo, que oferece ao leitor as ferramentas para compreender a questão em suas nuances. 
e assim por diante. Visualmente, os relatórios episódicos geram "boas fotos". 0 enquadramento temático da notícia, ao contrário, coloca as questões públicas em algum contexto geral ou abstrato. Relatórios sobre reduções nas despesas de bem-estar do governo, mudanças na natureza das oportunidades de emprego, as queixas sociais ou políticas de grupos que realizam atividades terroristas, mudanças na política federal de ação afirmativa ou o acúmulo no processo de justiça criminal são exemplos de cobertura temática. (IYENGAR, 1990, p. 7)

A título de exemplo, aplicando este conceito a uma das coberturas já citadas acima, pela análise dos casos de Jandira, Elizângela e da Operação Herodes (LUNA, 2014), a maior parte das matérias poderia ser considerada episódica. Os textos acompanham cada operação policial e não chegam a situar o acontecimento em um espectro maior sob o qual milhares de mulheres perdem suas vidas em tentativas malsucedidas de aborto clandestino.

Já V8) Tipos de Enquadramento deriva da síntese feita por Semetko e Valkenburg (2000) a partir de uma revisão de literatura de estudos de enquadramento nos Estados Unidos e na Europa. Embora esta variável se situe sob o escopo da terceira vertente das análises de enquadramento, a dos framing effects, acreditamos que a operacionalização destes conceitos enriquece a interpretação dos dados também numa dimensão metacomunicativa.

Nesta variável, a notícia é construída a partir de cinco frames ou quadros interpretativos:

1) Moralidade: direta ou indiretamente, por meio das fontes de informação entrevistadas, o tema é abordado sob um viés religioso, moral, filosófico ou ético, ao invés de prático, social ou cultural;

2) Responsabilidade: Quem deveria ser responsabilizado por isso? Essa é a pergunta central para entender este frame, cujas notícias atribuem a um indivíduo, grupo ou autoridade a responsabilidade por um problema;

3) Consequências Econômicas: quando a matéria apresenta um fato como parte de um contexto mais amplo, descrevendo seus impactos sociais, econômicas, políticas ou para a saúde pública de um grupo ou para outros indivíduos;

4) Interesse Humano: o conteúdo dramatiza a questão em torno de um personagem, que torna a questão palpável e humanizada, sem necessariamente aprofundar a questão; 
5) Conflito: a notícia reduz a discussão à apresentação de "dois lados" do assunto, de maneira quase simplista.

Uma notícia pode conter mais do que um frame, mas, para efeito desta análise, foi considerado apenas aquele que predominou em cada texto.

\subsection{Um retrato do aborto a partir da notícia}

A análise partiu de notícias publicadas em quatro portais: Folha de S. Paulo, 0 Estado de S. Paulo, Huffpost Brasil e Nexo Jornal. Os sites foram selecionados por oferecerem níveis significativos de audiência e alcance de público. Os dois primeiros são os sites dos maiores jornais brasileiros ${ }^{5}$, sendo que a Folha tem uma média de circulação mensal de 328.438 exemplares, e o Estadão tem circulação média mensal de 242.374 exemplares. Já as páginas Huffpost Brasil ${ }^{6}$ e Nexo Jornal são duas das mais acessadas entre os veículos classificados como nativos digitais, ou seja, aqueles veículos jornalísticos que já nasceram em um ambiente de internet. 0 primeiro teve 3,5 milhões de acessos em julho de 2020 e o segundo alcançou 2 milhões de visitas no mesmo período ${ }^{7}$. Optou-se por mesclar veículos tradicionais e outros nativos digitais para verificar também se haveria diferença no tipo de cobertura oferecida por ambos.

Foram analisadas 85 notícias focadas especificamente na questão do aborto, publicadas entre $1^{\mathrm{o}}$ de janeiro e 31 de dezembro de 2019. A coleta considerou apenas conteúdo jornalístico, excluindo as notícias que somente citavam a questão do aborto, sem oferecer centralidade ao tema. Textos opinativos em geral, como blogs, colunas, cartas do leitor e editoriais também não foram incluídos. Das notícias analisadas, 35 foram publicadas no Estadão, 32 na Folha, 12 no Huffpost Brasil e 6 no Nexo. A discrepância

\footnotetext{
5 “Circulação dos maiores jornais do País cresce em 2019”. Disponível em: <https://bit.ly/3uwXRxZ>. Acesso em 28/05/2021.

${ }^{6}$ Em novembro de 2020, após a realização da análise em tela, o site Huffpost Brasil anunciou o encerramento das suas atividades no Brasil depois de sete anos de atuação. Por conta disso, as matérias analisadas já não estão mais disponíveis online. Huffpost encerra atividades no Brasil após quase 7 anos no ar. Fonte: Poder 360. Disponível em: <https://www.poder360.com.br/midia/huffpost-encerraatividades-no-brasil-apos-quase-7-anos-no-ar/>. Acesso em 28/05/2021.

${ }^{7}$ Estes dados foram obtidos comparando os sites nativos digitais em um monitor de tráfego digital, o site SemRush. Fonte: https://pt.semrush.com/
}

Dossiê Feminismos vitais - https://revistaecopos.eco.ufrj.br/ 
entre as quantidades de materiais que circularam nos dois tipos de veículos era esperada, uma vez que Nexo e Huffpost guardam características de jornalismo independente, como equipes mais reduzidas e menor volume de matérias publicadas no geral.

44 textos $(51,8 \%)$ tratavam do assunto a partir de um ponto de vista favorável ao direito ao aborto, manifestado na seleção e nas falas das fontes e no tom dado na própria voz do repórter. Apenas cinco textos (5,9\%) eram claramente contrários - quatro dos quais estão no Estadão e um deles na Folha - e 36 (42,3\%) apresentaram neutralidade.

Se relacionados aos números encontrados por Melo em 1997, os dados atuais demonstram uma mudança do posicionamento dos veículos da imprensa no sentido favorável ao direito ao aborto, ainda que nos casos já permitidos pela legislação - ou seja, com um viés de fazer valer os direitos já adquiridos. Dos favoráveis, 19 estão na Folha, 12 no Estadão, 8 no Huffpost Brasil e 5 no Nexo. Apenas um dos textos do Nexo adota uma perspectiva de neutralidade, contra 4 do Huffpost Brasil, 12 da Folha e a maioria do Estadão - 19 notícias.

As matérias da Folha, do Huffpost Brasil e do Nexo são majoritariamente escritas por mulheres, enquanto que, no Estadão, 24 não são assinadas, 6 são de autores homens, 3 são de autoria coletiva e apenas duas foram escritas por mulheres. Apenas o Estadão traz textos com mais do que um autor. No Nexo, todas são escritas por Mulheres, e no Huffpost apenas uma não traz assinatura. Na Folha, 19 são assinadas por mulheres, 4 por homens e 9 não têm autoria declarada.

Os números refletem o cenário atual do jornalismo - onde mais de $60 \%$ das profissionais da área são mulheres (MICK, 2012) - e atendem às demandas do feminismo, que defende a igualdade de gênero no campo da produção de conteúdo, como um instrumento para pluralizar as vozes do jornalismo.

Para as jornalistas, o fato de mulheres estarem na redação escrevendo sobre temas relacionados às vivências próprias deste grupo representa um ponto de virada para jornalismo, enquanto processo de "tradução" da realidade. Em uma pesquisa com entrevistas do tipo survey com 94 jornalistas paulistas, Santos e Mateos identificaram que, embora a maioria das entrevistadas "reitere que as competências sejam as mesmas (72\%), as jornalistas participantes da pesquisa reconhecem que há um olhar diferenciado 
nas reportagens feitas pelo gênero feminino (35\%) e diferenças entre os pontos de vista na produção jornalística (38\%)" (SANTOS, MATEOS, 2019, p. 139).

Passando à questão das fontes de informação utilizadas, a cobertura midiática sobre a aborto trouxe Ativistas Favoráveis ao direito de abortar em 55\% dos textos, enquanto 29\% ouviram Ativistas Antiaborto. Metade das matérias incluem fontes Políticas, em geral parlamentares ou ministros - entre os quais a principal figura citada é a ministra da Mulher, da Família e dos Direitos Humanos do governo Jair Bolsonaro, Damares Alves, cujo posicionamento antiaborto é de conhecimento público.

Quase um terço dos textos (27\%), se pautam em fontes relacionadas a Saúde, presença equivalente à de fontes Jurídicas. Há também baixa prevalência de fontes unicamente Religiosas: apenas 11\% dos textos incluem padres, pastores ou fiéis.

Personagens também são raros: 13\% dos textos analisados contam a história a partir da perspectiva de uma mulher que tenha sofrido ou desejado sofrer um aborto, seja ele incluso ou não nos casos previstos pela legislação. 10\% das matérias trazem Outros Personagens e $18 \%$ dos textos se baseiam em Pesquisas, levantamentos ou dados públicos para justificar sua narrativa.

É relevante que, embora a discussão sobre aborto seja historicamente pautada em valores religiosos, especialmente por parte de quem se posiciona contra a interrupção voluntária da gestação, as reportagens analisadas muito raramente tragam este viés estritamente religioso para dentro das matérias em suas fontes.

Os contra-argumentos são, na maioria das matérias, feitos por ativistas antiaborto, defensores da vida desde a concepção, uma posição que pode ou não estar relacionada a valores religiosos. No caso das matérias analisadas, essas pessoas não ganham autoridade apenas especificamente por serem religiosas, mas como lideranças de organizações antiaborto ou representantes políticos - ainda que tenham sido eleitos com base em pautas religiosas. A fé não aparece retratada em primeiro plano, mas como acessória ou camuflada, de modo que a interpretação da notícia pode ser diferente para os sujeitos da audiência que já carregam um conhecimento prévio sobre a situação e para os que não o têm. 
Se comparado com resultados de pesquisas anteriores que buscam analisar as coberturas midiáticas, esse resultado se mostra um discrepante, uma vez que investigações como a de Luna (2014) revelam que a entrada de agentes católicos e evangélicos foi determinante no debate na imprensa sobre o tema em 2010, durante as já citadas eleições presidenciais. No entanto, a autora evidencia que a presença desses atores se dá principalmente como participantes de um “jogo político”, uma vez que aparecem como contestadores de um ou outro candidato, criticando-os publicamente.

Considerando o conjunto das matérias, pouco se expôs sobre a situação do aborto no Brasil, embora os autores dos artigos de opinião, os especialistas, os religiosos e os políticos consultados tivessem opinião a respeito. 0 tema do aborto, retratado na cobertura da imprensa em termos nitidamente estigmatizantes, foi associado, em proporção bem maior, à candidata do PT. (LUNA, 2014, p. 386)

Essa consideração feita pela autora após uma análise criteriosa do período préeleitoral em primeiro e segundo turno, na ocasião, evidencia como os agentes religiosos são claramente retratados como tal, antes mesmo de sua posição política. Machado (2012, p. 49), por sua vez, reconhece que, neste mesmo pleito, a atuação religiosa parece ter um efeito de reação a avanços na agenda progressistas que se faziam presentes por meios de movimentos como o feminista e o dos direitos LGBTQIA e que, já naquele momento, agentes religiosos com cargos políticos influenciavam a discussão de alguma forma.

Nos quase dez anos que se passaram desde então, a entrada desses agentes na política institucional. É o caso, por exemplo, da própria ministra Damares Alves. $\mathrm{Na}$ reportagem "Na ONU, ministra discursa contra aborto e diz que direito da mulher é prioridade"8, por exemplo, a Folha repassa algumas das falas da titular do Ministério da Mulher, da Família e dos Direitos Humanos durante a participação em um evento da Organização das Nações Unidas. A abordagem do texto é crítica a ela no sentido de questionar a ausência de políticas públicas para questões que atingem principalmente as mulheres. Contudo, embora a ministra seja uma figura religiosa, que pauta declaradamente sua atuação política em valores religiosos, essa característica não

8 "Na ONU, ministra discursa contra aborto e diz que direito da mulher é prioridade". Disponível em <https://bit.ly/34JOQs8>. Acesso em 28/05/2021.

Dossiê Feminismos vitais - https://revistaecopos.eco.ufrj.br/

ISSN 2175-8689-v. 24, n. 1, 2021

DOI: 10.29146/ecopos.v24i1.27609 
aparece no texto. Assim, o posicionamento contrário ao direito ao aborto é atribuído a uma autoridade política, não a uma pastora da igreja evangélica, papel que ela ocupa e que é de conhecimento público.

Essas nuances contribuem para transferir a discussão para o terreno da política afastando-a dos religiosos ou morais. 0 que não é possível responder sem empreender outros tipos de investigação é se isso se dá porque o debate está mais politizado ou porque os agentes religiosos estão mais presentes nessas classes políticas, conforme mencionado, à medida em que, ao invés de ostentar a etiqueta da religião, passaram a se identificar por seus cargos políticos, como acontece com a ministra.

No tópico a seguir, apresentamos a discussão dos resultados encontrados nas duas principais variáveis - Nível de contextualização e Tipo de Enquadramento -, a partir de alguns cruzamentos ilustrados com trechos das reportagens.

\section{Mergulhos pouco profundos}

A análise da cobertura midiática sobre o direito ao aborto ao longo de 2019 demonstra alguns avanços com relação ao que relatam pesquisas anteriores, no sentido de que os sites parecem estar menos resistentes para tratar do tema, mas os mergulhos no assunto ainda permanecem em águas rasas, na maior parte do tempo.

0 primeiro dado que conduz a essa observação é a predominância de enquadramento Episódico (73\%) sobre o Temático (27\%), o que era esperado, uma vez que a maior parte das matérias vêm de jornais diários, cuja cobertura é predominantemente factual. Na rotina acelerada das redações, especialmente na produção de conteúdo para a internet, as notícias tradicionalmente priorizam a velocidade de publicação, em detrimento da profundidade.

Entre os quality papers (GRÁFICO 01), a diferença é ainda maior, 84\% das notícias são episódicas. 0 peso maior sobre esse dado vem do Estadão, que traz 32 matérias Episódicas, contra apenas 3 Temáticas. Na Folha, o equivalente a um terço das notícias eram embasadas, apresentavam um contexto mais amplo, trazendo diferentes perspectivas sobre o tema e contextualizando a questão da saúde pública e o conflito moral e jurídico envolvido. 
GRÁFICO 01: NÍVEL DE CONTEXTUALIZAÇÃO

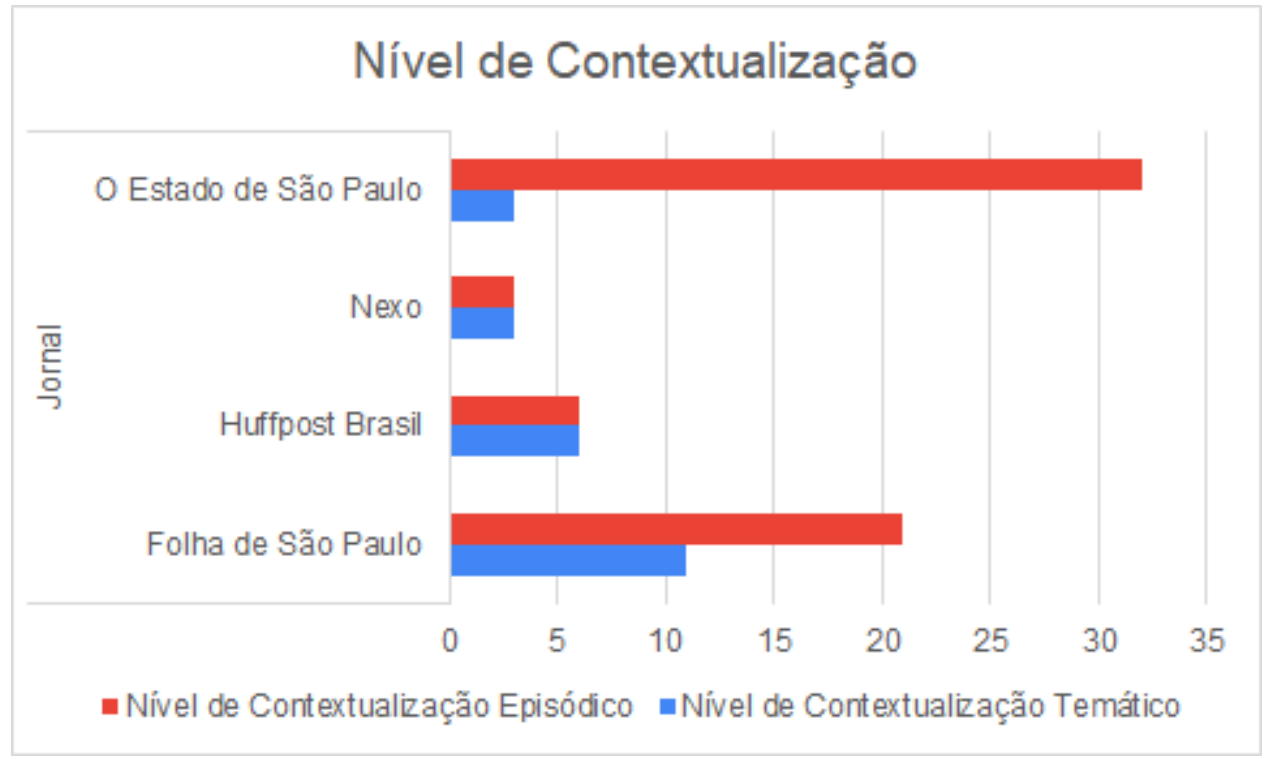

Fonte: as autoras

Ao longo de 2019, os principais ganchos para coberturas sobre o tema foram as múltiplas tentativas de pelo menos cinco estados norte-americanos de aprovar legislações locais mais restritivas para a interrupção da gestação.

Dois outros casos também se destacaram: o de uma mulher em El Salvador, Evelyn Hernández, que havia sido condenada pela justiça local por assassinato, ainda que a realização voluntária do aborto nunca tenha sido confirmada; e a cesárea performada em uma menina de 11 anos vítima de estupro na Argentina, em fevereiro de 2019. 0 primeiro aparece no Estadão e no Huffpost Brasil, com as matérias "Salvadorenha acusada de aborto enfrenta segundo julgamento por homicídio"9, "Salvadorenha é absolvida de acusação de assassinato de seu bebê"10 e "Justiça de El Salvador absolve jovem que deu à luz um bebê morto e foi acusada de abortar"11. Sobre o segundo episódio, a Folha de S.

\footnotetext{
9 "Salvadorenha acusada de aborto enfrenta segundo julgamento por homicídio". Disponível em: $<$ https://bit.ly/2QBWahb >. Acesso em 28/05/2021.

10 "Salvadorenha é absolvida de acusação de assassinato de seu bebê". Disponível em: <https://bit.ly/2QAIKSU>. Acesso em 28/05/2021.

11 "Justiça de El Salvador absolve jovem que deu à luz um bebê morto e foi acusada de abortar". Anteriormente disponível em: < https://bit.ly/32y8EME > . Acesso em: 17/08/2020
} 
Paulo publicou dois textos: "Em vez de aborto, médica faz cesárea em menina de 11 anos violentada na Argentina"12 e "Morre bebê de argentina de 11 anos submetida a cesárea em vez de aborto"13. No Estadão, apenas "Em vez de aborto, médicos decidem fazer cesárea em menina de 11 anos violentada na Argentina"14 trata do caso.

A Folha veiculou quase um texto Temático por mês. A matéria "Mesmo com debate constante, aborto ainda está sob lei da Era Vargas"15 ilustra os principais aspectos que foram considerados na codificação ao classificar um conteúdo como Temático: resgata, ainda que brevemente, o percurso da pauta nas esferas jurídicas ou legislativas e traz a perspectiva da saúde pública, apresentando as consequências da criminalização para a saúde e a estigmatização das mulheres.

Embora não fosse um pré-requisito para isso, foi possível perceber que a maior parte das matérias com contextualização Temática também apresentam multiplicidade de fontes, promovendo um diálogo entre os entrevistados para cobrir a pauta a partir de várias esferas.

O equilíbrio (50\%) entre os dois Níveis de Contextualização apresentado nos sites nativos digitais era inesperado. Partia-se da hipótese de que a cobertura dos nativos digitais seria Temática quase que na sua totalidade, uma vez que ambos costumam se deter mais tempo sobre as reportagens e são reconhecidos pelo conteúdo denso.

Os dados mostram, contudo, que mesmo entre os sites com características mais independentes e não ligados aos tradicionais conglomerados de mídia brasileiros, o nível Episódico aparece com equivalência, desenhando um cenário no qual os veículos noticiosos seguem priorizando a factualidade em detrimento da profundidade.

Pesquisas anteriores obtiveram resultados similares. Em uma análise da abordagem dada por diferentes sites e jornais ao uso ilegal do medicamento misoprostol,

\footnotetext{
12 "Em vez de aborto, médica faz cesárea em menina de 11 anos violentada na Argentina". Disponível em: $<$ https://bit.ly/3jqjGtW>. Acesso em 28/05/2021.

13 "Morre bebê de argentina de 11 anos submetida a cesárea em vez de aborto". Disponível em: $<$ https://bit.ly/34KNEFc >. Acesso em 28/05/2021.

14 "Morre bebê de argentina de 11 anos submetida a cesárea em vez de aborto" Disponível em: <https://bit.ly/2E00Ga0 >. Acesso em 28/05/2021.

15 "Mesmo com debate constante, aborto ainda está sob lei da Era Vargas". Disponível em: <https://bit.ly/31BLDJa> Acesso em 28/05/2021.
} 
principal pílula utilizada para o abortamento clandestino no Brasil, Diniz e Castro (2011, p. 100) perceberam "um deslocamento do tema do aborto com a entrada do medicamento nas práticas abortivas. As matérias abandonam o debate fundamentalmente moral e se concentram em denúncias e apreensões de medicamentos comercializados ilegalmente".

Essa mudança, tanto no trabalho das autoras quanto nesta pesquisa em tela, mostra presença maior de agentes políticos e da área da Saúde, o que pluraliza o debate, mas não necessariamente aprofunda o tratamento que é dado aos temas.

É possível entrevistar agentes de saúde, advogados e parlamentares e, ainda assim, manter o debate no campo das especificidades, sem expandir a discussão. Na perspectiva das autoras, essa expansão seria essencial para garantir ao público feminino todas as informações necessárias para conhecimento do tema.

\begin{abstract}
O silenciamento de vozes médicas e de movimentos de mulheres, bem como a não divulgação de informações sobre o efeito do misoprostol para a redução da morbimortalidade materna, ocultam a abordagem do aborto seguro como tema de saúde e de direito das mulheres. (DINIZ, CASTRO, 2011, p. 101)
\end{abstract}

A cobertura, mesmo a Temática, continua negligenciando o fator interseccional do aborto no Brasil, ignorando, na maior parte do tempo, os recortes de raça e classe. Mas, ao menos no que diz respeito às fontes no sentido discutido por Diniz e Castro, as notícias publicadas em 2019 avançam, ainda que timidamente, em relação às situações observadas por elas em 2011, ao incluir essas vozes e ampliar as tônicas da saúde, do direito e da autonomia feminina.

As matérias Temáticas exemplificam essa evolução: são textos com teor explicativo sobre a evolução histórica do tratamento do direito ao aborto ou sobre impactos, o posicionamento e a polarização dos profissionais de saúde, bem como as consequências da estigmatização do aborto mesmo para a saúde reprodutiva daquelas que não precisam do aborto. É o caso da matéria "O que é misoprostol. E os problemas se ele faltar no SUS"16, do Nexo.

16 "O que é misoprostol. E os problemas se ele faltar no SUS”. Disponível em: <https://bit.ly/3jhKI6S>. Acesso em 28/05/2021.

Dossiê Feminismos vitais - https://revistaecopos.eco.ufrj.br/

ISSN 2175-8689 - v. 24, n. 1, 2021

DOI: 10.29146/ecopos.v24i1.27609 
O site veiculou ainda duas outras matérias com Contextualização Temática: “A origem e a legalidade das vigílias contra o aborto legal"17 e "0 conselho de medicina diante da saúde das mulheres"18. No caso do Huffpost Brasil, entre as seis matérias categorizadas como Temáticas estão "Mulheres se sentem incapazes de contar para alguém que o aborto é uma opção para elas"19, que apresenta uma perspectiva humanizadora das entrevistadas, discutindo as barreiras que enfrentam quando tomam a decisão de interromper a gestação, e "Por que o direito ao aborto legal ficou de fora da Constituição de 1988"20, que resgata os olhares das mulheres responsáveis por incentivar a inclusão de pautas de gênero durante a Constituinte.

É possível replicar, de certa forma, a linha de raciocínio que Iyengar (1990) desenvolve ao questionar coberturas de atos terroristas ou de campanhas eleitorais. Segundo ele, quando o enquadramento episódico predomina sobre o temático, o público se alimenta do que recebe e tende a relacionar o assunto àquela visão limitada.

Se a cobertura do terrorismo se concentra sobre o sujeito que cometeu um ato terrorista, as características atribuídas a este sujeito serão a ferramenta que o público tem para reconhecer outros terroristas - daí o reforço do estigma.

No caso do direito ao aborto, se as reportagens estão focadas apenas em apresentar um caso em específico, sem atrelar aquele caso ao histórico da discussão sobre o tema no país, às situações e riscos aos quais as mulheres estão sujeitas ao recorrer à clandestinidade, sem apresentar as implicações do aborto para a saúde pública nacional, a cobertura tende a incentivar que o "problema" reside naquela mulher, e não na abordagem que o país dá à questão em termos de saúde, direitos, políticas públicas.

As implicações normativas dos efeitos da acessibilidade induzidos pela mídia não são claras. 0 exercício da cidadania esclarecida exige que a complexidade da coisa pública seja de alguma forma superada e o viés da acessibilidade é certamente um meio conveniente para isso. A questão importante é até que

\footnotetext{
17 “A origem e a legalidade das vigílias contra o aborto legal". Disponível em: <https://bit.ly/3jnuqcC>. Acesso em 28/05/2021.

18 "O conselho de medicina diante da saúde das mulheres". Disponível em: <https://bit.ly/31CReim>. Acesso em 28/05/2021.

19 "Mulheres se sentem incapazes de contar para alguém que o aborto é uma opção para elas". Anteriormente disponível em: <https://bit.ly/32yPsOB>. Acesso em 17/08/2020.

20 "Por que o direito ao aborto legal ficou de fora da Constituição de 1988". Anteriormente disponível em: $<$ https://bit.ly/2EF5RZD>. Acesso em 17/08/2020.
} 
ponto as 'imagens em suas cabeças' ajudam os cidadãos a fazer as escolhas 'certas'. Um eleitor agindo de acordo com o viés de acessibilidade chegaria ao mesmo resultado se dotado de informações perfeitas e um processo de escolha 'detalhado, exato e criativo'? (IYENGAR, 1990, p. 12)

Mesmo assim, é mais importante que o tema seja tratado pela imprensa do que ignorado sumariamente, já que trazer a pauta para discussão pública colabora para a redução do estigma. Conforme observa Iyengar (1990), trata-se de uma questão de acessibilidade, no sentido de tornar as informações acessíveis ao público. Porém, há que se ressaltar que uma cobertura noticiosa limitada não é capaz de munir o público com todas as ferramentas para que possa avançar na discussão.

Embora a visão de Iyengar flerte com a terceira vertente dos estudos de enquadramento, a dos frame effects, entendemos que a observação destes dois tipos de frames contribui para a fase metadiscursiva da análise, no sentido de que é nas escolhas da construção do texto que se evidencia o direcionamento da matéria.

Este aspecto está relacionado, por exemplo, à já citada questão da interseccionalidade, bem como à perspectiva de quem construiu o texto e com base em quais informações. As jornalistas mulheres assinam 18 das 23 matérias que empregam um Nível de Contextualização Temático, que só aparece em um texto de autoria masculina.

Em parte, esse resultado tem relação com a presença maior de mulheres nas redações, conforme apontado anteriormente. Por outro lado, cabe o questionamento: essas pautas são atribuídas a elas nas redações por conta de seu gênero ou a mulheres apresentam abordagens mais contextualizadas do tema do que os homens? Para responder a essa pergunta, seria necessário recorrer às redações para entrevistar jornalistas mulheres e compreender o contexto de produção dessas notícias.

Nossa hipótese, a partir desses dados, é a de que a descriminalização do aborto é uma pauta que interessa mais às mulheres, enquanto os homens ainda encontram pouco estímulo para se aprofundar no tema. Essa "preferência" também teria relação com o fato de que a responsabilidade sobre a gestação e criação dos filhos historicamente recai sobre a mulher, de maneira que a atribuição deste tipo de pauta às jornalistas mulheres possa 
ser considerado como algo natural na rotina das redações, espaço que também é marcado por estereótipos de gênero.

\subsection{Menos moral, mais social}

No que diz respeito aos tipos de enquadramento, a perspectiva do Conflito não é a predominante na cobertura, contrariando outra hipótese da qual se partia no início da pesquisa. Por se tratar de um tema polarizado e que costuma gerar discussões inflamadas nos moldes "contrários vs favoráveis", esperava-se que mais matérias trouxessem esta tônica.

Essa, de fato, aparece muito - em 24,7\% dos casos. Mas o da Responsabilidade, que olha para a questão do aborto tentando atribuir o problema a um órgão ou grupo responsável, é mais recorrente (28,2\%). São, em geral, reportagens que levantam números sobre mortalidade de mulheres em decorrência da criminalização, apontando o Estado como agente que deveria propor soluções.

O frame das Consequências Econômicas, com reportagens que implicam o custo financeiro, social e humano da criminalização do aborto, é o terceiro mais aparente (18,8\%). Está muito próximo ao do Interesse Humano $(17,6 \%)$, que traz como aspecto central a história de personagens e suas sagas pessoais relacionadas a uma gestação indesejada, valendo-se delas para abordar a questão. 0 frame da Moralidade é o menos aparente $(10,6 \%)$, o que dialoga com a baixa presença de matérias contrárias ao direito do aborto, uma vez que diz respeito aos conteúdos jornalísticos que imprimem no texto um viés religioso ou moral.

Somados, os frames de Responsabilidade e Consequências Econômicos correspondem a quase metade do corpus (47\%), um peso maior do que se considerada a soma do conteúdo centrado em Moralidade e Conflito (35,3\%). Assim, as notícias publicadas ao longo de 2019 não deixam de lado os conflitos morais, mas em seu conjunto, parecem estar caminhando para um viés mais preocupado com as implicações práticas, sociais e coletivas do que com um debate filosófico sobre a vida começar na concepção ou no nascimento, conforme costuma acontecer nas discussões na esfera política ou mesmo em debates informais sobre o tema (RIZZOTTO, BELIN, 2019). 
Contrapondo os frames e sua prevalência em cada site analisado (GRÁFICO 02), o Estado de S. Paulo é o que mais atribui Responsabilidade, viés preferido também pelo Nexo, enquanto Consequências Econômicas é predominante na Folha S. Paulo.

\section{GRÁFICO 02: TIPO DE ENQUADRAMENTO POR SITE ANALISADO}

\section{Tipo de Enquadramento x Site}

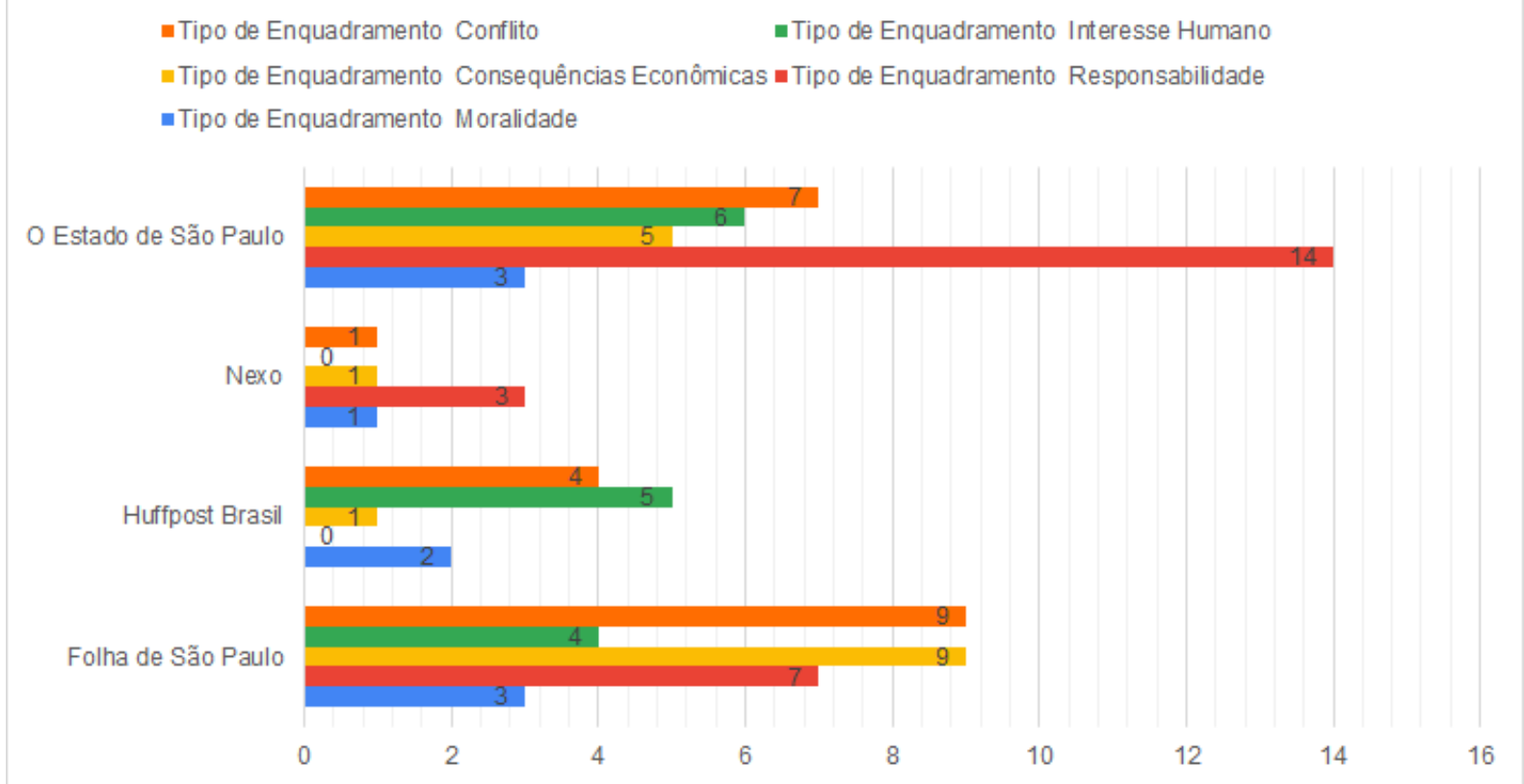

Fonte: as autoras

Ainda com relação à Folha de S. Paulo, as matérias que focam no Conflito aparecem em igual intensidade às que adotam a abordagem das Consequências Econômicas. Já as matérias do Huffpost Brasil são majoritariamente centradas num Viés Humano e nenhuma delas trata o tema com a perspectiva da Responsabilidade.

No cruzamento entre tipo de enquadramento e nível de contextualização (GRÁFICO 03), percebe-se que todas as matérias com o frame da Moralidade são Episódicas, o que indica que, mesmo quando o conteúdo se debruça sobre uma situação factual ou específica, a questão pode ser tratada de maneira a responsabilizar os sujeitos e não o coletivo, conforme tratado anteriormente a partir de Iyengar (1990). 
GRÁFICO 03: CRUZAMENTO ENTRE TIPO DE ENQUADRAMENTO E NÍVEL DE CONTEXTUALIZAÇÃO

Tipo de Enquadramento x Nível de Contextualização

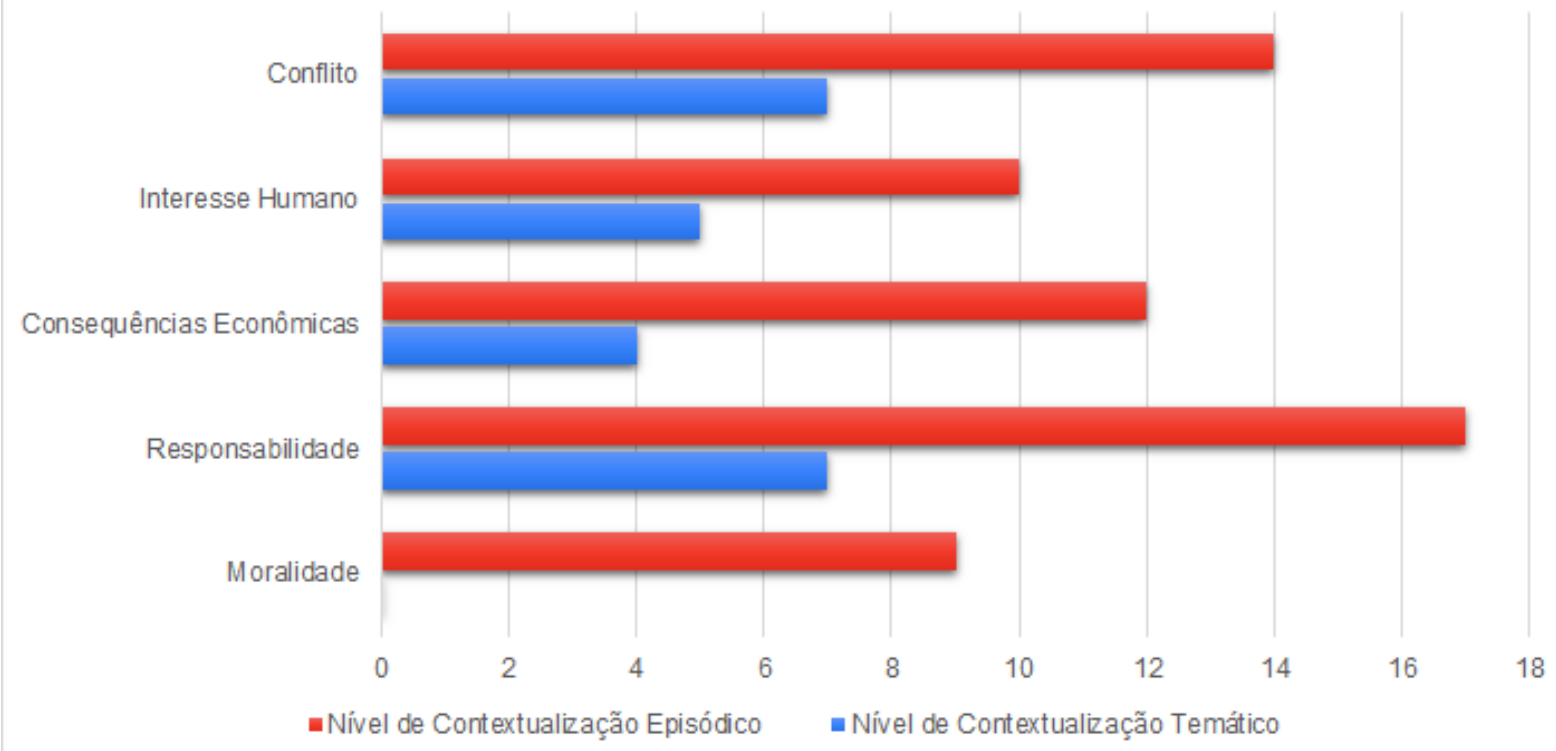

Fonte: as autoras

Assim como em Semetko e Valkenburg (2000), a pesquisa em tela identificou que o predomínio de conteúdos Episódicos não impede a atribuição de responsabilidade ao Estado ou a entidades públicas. Pelo contrário: a maior parte dos textos com esse tipo de olhar adota o frame da Responsabilidade (17 textos). "Nosso estudo mostrou que as notícias da televisão podem ser episódicas e, ao mesmo tempo, enquadrar o governo (e não o indivíduo) como responsável pelos problemas sociais" (SEMETKO, VALKENBURG, 2000, p. 106).

No caso das notícias sobre aborto, a maior parte das Episódicas com enquadramento de Responsabilidade tratam de avanços na descriminalização do aborto. "Nova Zelândia anuncia reforma para descriminalizar aborto"21, publicada pelo Estadão, é um exemplo. 0 texto reforça o papel do Parlamento na tarefa de aprovar um projeto de lei que permita a interrupção da gestação voluntariamente até a $20^{\text {a }}$ semana, enfatizando que este ainda é o único procedimento médico criminalizado no país.

21 "Nova Zelândia anuncia reforma para descriminalizar aborto". Disponível em: <https://bit.ly/2QwSq0w>. Acesso em 28/05.2021.

Dossiê Feminismos vitais - https://revistaecopos.eco.ufrj.br/ 
Na Folha, "Senado desarquiva projeto que impede novas possibilidades para realização de aborto"22, por sua vez, faz alusão à polarização do tema, chega a citar quais são os casos em que o aborto é permitido no Brasil, mas o faz apenas superficialmente, trazendo opiniões de senadores e atribuindo ao Senado Federal o papel de legislar sobre o tema.

Estes resultados, que dialogam com análises similares integradas aos feminist media studies, sugerem que ainda não é possível desvincular as discussões sobre a interrupção da gestação, seja ela clandestina ou nos casos previstos por lei, da polarização entre ativistas favoráveis e contrários. Apesar disso, é inegável que a cobertura fez tímidas tentativas no sentido de avançar a discussão a níveis mais aprofundados e embasados, contribuindo para debates mais consistentes sobre o tema na esfera pública. Ainda assim, a cobertura jornalística não reflete a opinião da população sobre o direito ao aborto, conforme os dados apresentados na introdução deste artigo.

\section{Considerações Finais}

A análise de 85 notícias publicadas em quatro portais de notícias - a saber: Folha de S. Paulo, O Estado de S. Paulo, Nexo Jornal e Huffpost Brasil -, a partir de oito variáveis delineadas com base na literatura sobre Enquadramento revelou que a cobertura noticiosa sobre a temática do aborto ao longo do primeiro ano de governo Jair Bolsonaro, 2019, se voltou para perspectivas conflituosas e de moralidade, com uma tímida movimentação de relacionar os conteúdos sobre o tema a aspectos sociais e de saúde pública.

Especialmente considerando os resultados provenientes das variáveis Nível de Contextualização [V7] e Tipos de Enquadramento [V8] (SEMETKO; VALKENBURG, 2000; IYENGAR, 1990; SILVA, 2017), identificou-se a predominância de notícias Episódicas, ou seja, aquelas que apenas apresentam situações específicas ou factuais, sem contextualizar ou aprofundar a discussão, mostrando suas causas e consequências e entrevistando pessoas com diferentes pontos de vista. A discrepância e maior entre os sites de jornais

22 "Senado desarquiva projeto que impede novas possibilidades para realização de aborto". Disponível em: $<$ https://bit.ly/2Qz92Vl>. Acesso em 28/05.2021.

Dossiê Feminismos vitais - https://revistaecopos.eco.ufrj.br/

ISSN 2175-8689-v. 24, n. 1, 2021

DOI: 10.29146/ecopos.v24i1.27609 
mais tradicionais, especialmente no Estadão, onde apenas três das notícias analisadas são Temáticas.

Ainda que pouco aprofundada, essa abordagem apressada do tema consegue ter um direcionamento menos polarizado, menos focado na moralidade e na polarização entre contrários e favoráveis. A análise identificou uma predominância dos frames da Responsabilidade e de Consequências Econômicas do aborto, acima dos frames de Conflito e Moralidade. Com isso, inferimos que, embora não aprofunde, a imprensa direciona o foco do assunto, atribuindo a responsabilidade ao Estado brasileiro e posicionando a discussão no terreno da saúde pública e da justiça, e não apenas na disputa moral e religiosa.

Percebe-se, também, que o primeiro ano do governo de Jair Bolsonaro na presidência não tornou a cobertura mais tímida, pelo contrário: a atuação de representantes da administração pública, como a ministra Damares Alves, chegou a pautar alguns sites. 0 próprio Jair Bolsonaro, no entanto, praticamente não aparece nos conteúdos analisados.

A pesquisa evidenciou a presença de ativistas legalistas, ou seja, pelo direito ao aborto, como fontes de informação das matérias, figurando em 55\% dos textos analisados, e a tendência a usar mais fontes políticas (50\%) do que religiosas (11\%). Esses dados indicam uma certa evolução da cobertura no sentido progressista, se comparados com estudos anteriores citados no artigo. Ainda que se considere que a esfera religiosa atravessa a política com uma certa concretude - a própria ministra Damares Alves é um exemplo - durante o período analisado, a diferença entre os percentuais continua sendo significativa. A presença ainda minoritária de fontes relativas à Saúde e ao Direito sugere que a pauta ainda esbarra nas barreiras da polarização política e moral, com apenas alguns casos pontuais em que consegue extrapolar o escopo da dualidade antiaborto $\mathrm{x}$ legalistas.

Contudo, é importante frisar que esse viés religioso aparece apenas no tipo de fonte e nas falas dessas fontes, já que o conteúdo do texto de maneira geral não engloba aspectos do tipo. Cabe continuar acompanhando a cobertura destes veículos durante os quatro anos de mandato presidencial, para medir a evolução da cobertura sobre o tema. 
Outra questão interessante observada informalmente ao analisar as reportagens é que as matérias já não trazem com frequência a expressão "pró-vida", convencionada para definir os ativistas contrários ao aborto. Ao invés da oposição entre pessoas "pró-vida" e "pró-aborto", se fala em pessoas "anti-aborto" versus "legalistas", exceto quando os termos aparecem nos nomes das organizações. Essa perspectiva pode ser um caminho pertinente para análises futuras, que foquem na importância da escolha dos termos pela classe jornalística e as consequências disso para o debate público sobre aborto.

\section{Referências bibliográficas}

ANIS Instituto de Bioética. Aborto: por que precisamos descriminalizar? Argumentos apresentados ao Supremo Tribunal Federal na Audiência Pública da ADPF 442. Brasília: LetrasLivres, 2019.

CUKIERKORN, Priscilla de Salles. BATISTA, Cicélia Pincer. O Enquadramento do Aborto na Mídia Brasileira: A Construção Jornalística do Direito de Autonomia Reprodutiva da Mulher. Anais do XXI Congresso de Ciências da Comunicação na Região Sudeste - SP, 2016. Disponível em: <https://www.portalintercom.org.br/anais/sudeste2016/resumos/R530930-1.pdf> . Acesso em: 28/05/2021.

DINIZ, Debora; MEDEIROS, Marcelo; MADEIRO, Alberto. Pesquisa nacional de aborto 2016. Revista Ciência e Saúde Coletiva, Rio de Janeiro, v. 22, n. 2, fev/ 2017. Disponível em: <https://bit.ly/2BXRtK9>. Acesso em: 17/08/2020

DINIZ, Debora; CASTRO, Rosana. O comércio de medicamentos de gênero na mídia impressa brasileira: misoprostol e mulheres. Cad. Saúde Pública, Rio de Janeiro, 27(1):94102, jan, 2011

FONTES, Maria Lucineide Andrade Fontes. 0 enquadramento do aborto na mídia impressa brasileira nas eleições 2010: a exclusão da saúde pública do debate. Ciência \& Saúde Coletiva, 17(7):1805-1812, 2012.

IYENGAR, SHANTO. The accessibility bias in politics: television news and public opinion. International Journal of Public Opinion Research, Vol 2, № 1, 1990.

LUNA, Naara. A controvérsia do aborto e a imprensa na campanha eleitoral de 2010. Cad. CRH, Ago 2014, vol.27, no.71, p.367-391.

Dossiê Feminismos vitais - https://revistaecopos.eco.ufrj.br/

ISSN 2175-8689-v. 24, n. 1, 2021

DOI: 10.29146/ecopos.v24i1.27609 
LUNA, Naara. Morte por aborto clandestino na imprensa: Jandira, Elizângela e Operação Herodes. Estudos Feministas, Florianópolis, 25(3): 530, set-dez/2017. http://dx.doi.org/10.1590/1806-9584.2017v25n3p1159.

MACHADO, Maria das Dores Campos. Aborto e ativismo religioso nas eleições de 2010. Rev. Bras. Ciênc. Polít., Abr.2012, n.7, pp. 25-54.

MANTOVANI, Denise. Mídia e estereótipos: as representações da diversidade social no discurso jornalístico. IN: MARQUES, Danusa. REZENDE, Daniela. MANO, Maira K. SARMENTO, Rayza. FREITAS, Viviane G. (org). Feminismos em Rede. Porto Alegre: Zouk, 2019.

. O aborto e as eleições de 2010: o papel do jornalismo na definição de discursos conservadores. IN: BIROLI, Flávia. MIGUEL, Luis Felipe. (orgs) Aborto e Democracia. São Paulo: Alameda, 2016.

MELO, Jacira. "A polêmica do aborto na imprensa”. Revista Estudos Feministas, v. 5, n. 2, p. 406-412, 1997.

MENDONÇA, Ricardo Fabrino. SIMÕES, Paula Guimarães. Enquadramento: Diferentes operacionalizações analíticas de um conceito Revista Brasileira de Ciências Sociais. Vol. 27, no 79. Junho de 2012.

MICK, Jackes. Quem é o jornalista brasileiro? Perfil da profissão no País. Programa de PósGraduação em Sociologia Política UFSC, 2012. Disponível em: $<$ https://perfildojornalista.ufsc.br/>. Acesso em 28/05/2021.

MIGUEL, Luis Felipe. 0 direito ao aborto como questão política. IN: BIROLI, Flávia. MIGUEL, Luis Felipe. (orgs) Aborto e Democracia. São Paulo: Alameda, 2016.

PINHO, Andrea Azevedo. 0 debate sobre o aborto no Brasil: enquadramentos midiáticos, conseqüências políticas. Monografia (Graduação em Ciência Política) - Universidade de Brasília, Brasília, 2008. IN: MIGUEL, Luis Felipe. Aborto e democracia. Estudos Feministas, Florianópolis, 20(3): 384, set-dez/2012

RIZZOTTO, Carla C., BELIN, Luciane L. Debate além da fronteira: características deliberativas da conversação de brasileiros sobre a [não] descriminalização do aborto na Argentina. Anais do 8o Encontro da Compolítica, Brasília, 2019.

SANTOS, Marli. MATEOS, Jéssica Oliveira Collado. Mulheres no jornalismo contemporâneo: desafios das tecnologias digitais. Comunicação \& Inovação, PPGCOM/USCS. v.20, n. 42 [124-143] jan-abr 2019

SARMENTO, Rayza. Feminismos e Comunicação: feminismo, mídia e política. IN: MARQUES, Danusa. REZENDE, Daniela. MANO, Maira K. SARMENTO, Rayza. FREITAS, Viviane G. (org). Feminismos em Rede. Porto Alegre: Zouk, 2019. 
SEMETKO, Holli. VALKENBURG, Patti. Framing European politics: a content analysis of press and television news. Journal of Communication, Vol. 50, Issue 2, Jun. 2000, pg. 93109.

SILVA, Paulo F. A batalha das biografias na arena midiática da democracia: uma análise de enquadramento da deliberação mediada jornalística. 2017. Dissertação (Mestrado do Programa de Pós-Graduação em Comunicação) - Universidade Federal do Paraná. 